\title{
Evaluation of an occipito-cervico fusion with a new implant design: a biomechanical study
}

\author{
Filippo Migliorini ${ }^{1 *} \mathbb{D}$, Alice Baroncini ${ }^{1 \dagger}$, Yasser El Mansy ${ }^{2}$, Valentin Quack ${ }^{2}$, Andreas Prescher ${ }^{3}$, Max Mischer ${ }^{1}$, \\ Johannes Greven ${ }^{2}$, Markus Tingart ${ }^{1}$ and Jörg Eschweiler ${ }^{1}$
}

\begin{abstract}
Background: A novel implant for occipitocervical fusion consisting of a median plate with an additional hook inserting in the foramen magnum was tested. Aim of this study was to test the stability of a new implant for occipitocervical fusion against the already available and employed median plate implant without hook.
\end{abstract}

Material and method: 36 rigid polyurethane foams occipital artificial bones were used. The two occipital implants, namely the occipital plate with hook (Group 1) and the one without hook (Group 2), were applied to the artificial occiput trough three occipital screws and ensured into the experimental setup trough a crossbar. The test parameters were set using the testing machine software as follows: (1) test speed: $10 \mathrm{~mm} / \mathrm{min}$, with $25 \mathrm{~mm} / \mathrm{min}$ maximum; (2) preload: $5 \mathrm{~N}$; (3) force switch-off threshold: $90 \%$ force drop from F_max. Failure force and path were recorded. Failure force is defined as the maximum reaction force under which failure occurs (F_max), while failure path is the travel path during which failure occurs $(\mathrm{dL})$.

Results: Group 1 (plate with hook) showed a mean failure force of $459.3 \pm 35.9 \mathrm{~N}$ and a mean failure path of $5.8 \pm$ $0.3 \mathrm{~mm}$ Group 2 (plate without hook) showed a mean failure force of $323.9 \pm 20.2 \mathrm{~N}$ and a mean failure path of $7.2 \pm 0.4 \mathrm{~mm}$. The Shapiro-Wilk test score was not significant $(P>0.1)$, assuming that data were normally distributed. Group 1 had a statistically significant greater $F_{-} \max (+135.37 ; P>0.0001)$ and less $\mathrm{dL}(-1.52 ; P>$ 0.0001) compared to group 2.

Conclusions: Medial plates with foramen magnum hooks showed to be more stable that plates without a hook. These new implants may represent a new tool in OCJ fixation, but further studies are required to investigate their behavior in an anatomical setting.

\section{Background}

The occipitocervical junction (OCJ) is the transitional region between the cranium and the spine and represents the most mobile area of the cervical spine. The occiput $(\mathrm{C} 0)-\mathrm{C} 1$ joint is the biggest contributor to the flexion and extension movements $\left(21^{\circ}\right.$ and $3.5^{\circ}$,

\footnotetext{
* Correspondence: migliorini.md@gmail.com

${ }^{\dagger}$ Filippo Migliorini and Alice Baroncini contributed equally to this work. ${ }^{1}$ Department of Orthopaedic Surgery, RWTH Aachen University Hospital, Pauwelsstraße 30, 52074 Aachen, Germany

Full list of author information is available at the end of the article
}

respectively), while the segment $\mathrm{C} 1-\mathrm{C} 2$ is responsible for axial rotation (about $25-35^{\circ}$ per side) [1]. This complex anatomical region is rich in membranes and synovial joints [1]. Posterior occipitocervial arthrodesis in indicated for in stability of the OCJ [2,3]. Given the complex anatomy and biomechanics, the rate of failure for external fixators for OCJ instability is up to $30 \%$ [4] Thus, a novel implant for a more stable internal, surgical fixation is required.

Concentrating on the occipital part of the implants, instrumentation of this area represents a challenge for the

(c) The Author(s). 2021 Open Access This article is licensed under a Creative Commons Attribution 4.0 International License which permits use, sharing, adaptation, distribution and reproduction in any medium or format, as long as you give appropriate credit to the original author(s) and the source, provide a link to the Creative Commons licence, and indicate if changes were made. The images or other third party material in this article are included in the article's Creative Commons licence, unless indicated otherwise in a credit line to the material. If material is not included in the article's Creative Commons licence and your intended use is not permitted by statutory regulation or exceeds the permitted use, you will need to obtain permission directly from the copyright holder. To view a copy of this licence, visit http://creativecommons.org/licenses/by/4.0/. The Creative Commons Public Domain Dedication waiver (http://creativecommons.org/publicdomain/zero/1.0/) applies to the data made available in this article, unless otherwise stated in a credit line to the data. 
surgeon due to its anatomical peculiarities $[4,5,6]$. The occipital protuberance is its thickest bony part, but the thickness is not uniform and gradually decreases laterally and caudally [7], so that in some settings even the shortest provided screws may be too long or the length of the screw would not provide sufficient stability [8]. Many occipital implants have been proposed, but no consensus has yet been reached $[4,8]$. Techniques that have been employed include the use of rods attached to wires and onlay bone grafting with wire fixation. Hook and rod constructs were attempts at mitigating wire-cutting complications while providing stability to the cervical spine, and OCJ, respectively [9]. Most screw/plate constructs allow a degree of rotation of the screw head in respect to the plate, which over time can lead to reduction of the implant stability and, eventually, pullout [4]. For this reason, and also to reduce iatrogenic complications such as lesion of the meningeal sheets or the venous plexus alternative implants such as occipital-condyle screw plates or bone hooks have been developed $[8,10$, $11]$.

In this work, we present a novel implant (Medicon, occiput plate) consisting of a median plate with a hook inserting in the foramen magnum. Historically, stabilization of the craniocervical junction consisted of onlay bone grafting with posterior wiring. Aim of this study was to test the stability of a new implant with an additional hook for bone fixation against the already available and employed median plate implants.

\section{Methods}

\section{Implants and test specimen}

For implant testing, 36 artificial occipital bones made of rigid polyurethane foams (Sawbone ${ }^{\circ}$, Pacific Research Laboratories Inc., Vashon, Washington, USA) that complied with the requirements ASTM F1839-08 [12] were used. Eighteen artificial bones were available for each of the two examined group. The two occipital implants (Fig. 1) (Medicon, occiput plate, made of Ti-6AI-4 V surgical alloy), namely the occipital plate with hook (Group 1 ) and the one without hook (Group 2), were applied to the artificial occiput trough three occipital screws. The implants were manufactured via milling without a special postprocessing. The implants were fixed by an experienced surgeon. Other than the presence of the hook, the plates were identical in shape and material. The construct consisting of artificial occiput, plate, screws and crossbar were ensured into the experimental setup trough a crossbar (Fig. 1).

\section{Experimental test setup}

An experimental test setup was developed to examine and analyse the implants (Fig. 2). The experimental setup consisted of aluminum profiles (Item - Solingen, Germany), which were connected together to function as frame to fix the artificial bone. A fastening claw made of two force carriers was used to clamp the crossbar and served as a connecting piece between the force transducer and the implant. Axial pullout forces were applied to the implants on all artificial bones using a custommade jig attached to a servohydraulic universal material testing machine (MTM) (Zwick and Roell - Ulm, Germany). The force transducer of the MTM was used to measure the applied force: with an accuracy class of 1 , this instrument has a maximum measurement deviation of $1 \%$.

\section{Preparation}

The same preparation procedure was used for both experimental groups. First, a template implant was placed above the artificial occiput to mark three central drill holes along the internal occipital crest. Then an awl was pierced into the three markings to ensure precise placement of the holes. With a $3.5 \mathrm{~mm}$ drill, three holes were

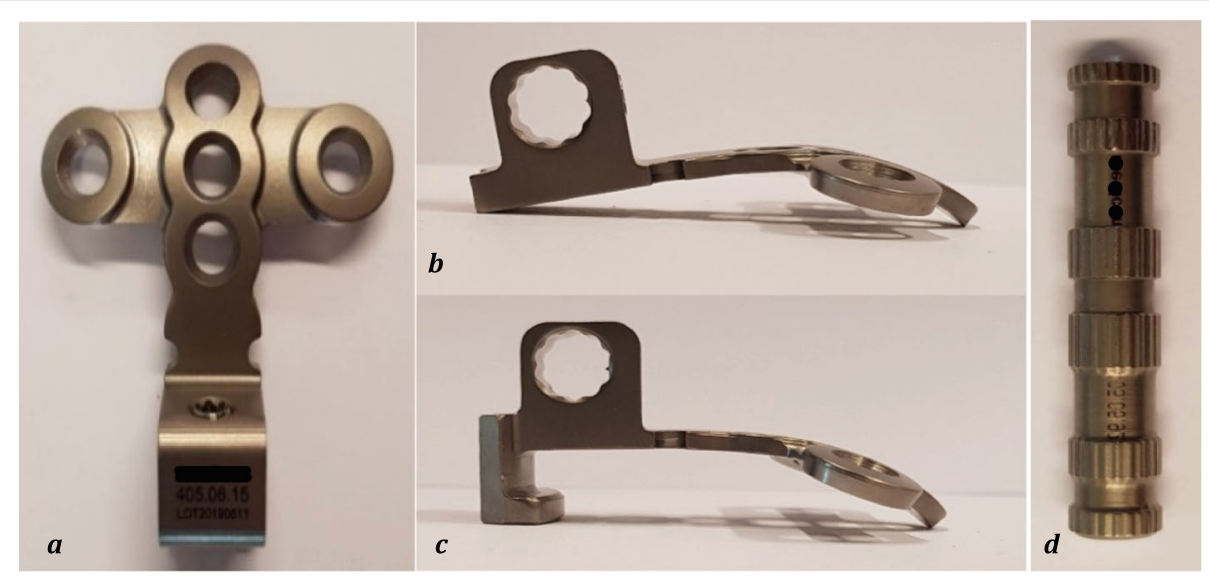

Fig. 1 Occipital plate (a: dorsal view; b: lateral view without hook; c: lateral view with hook; d: crossbar) 


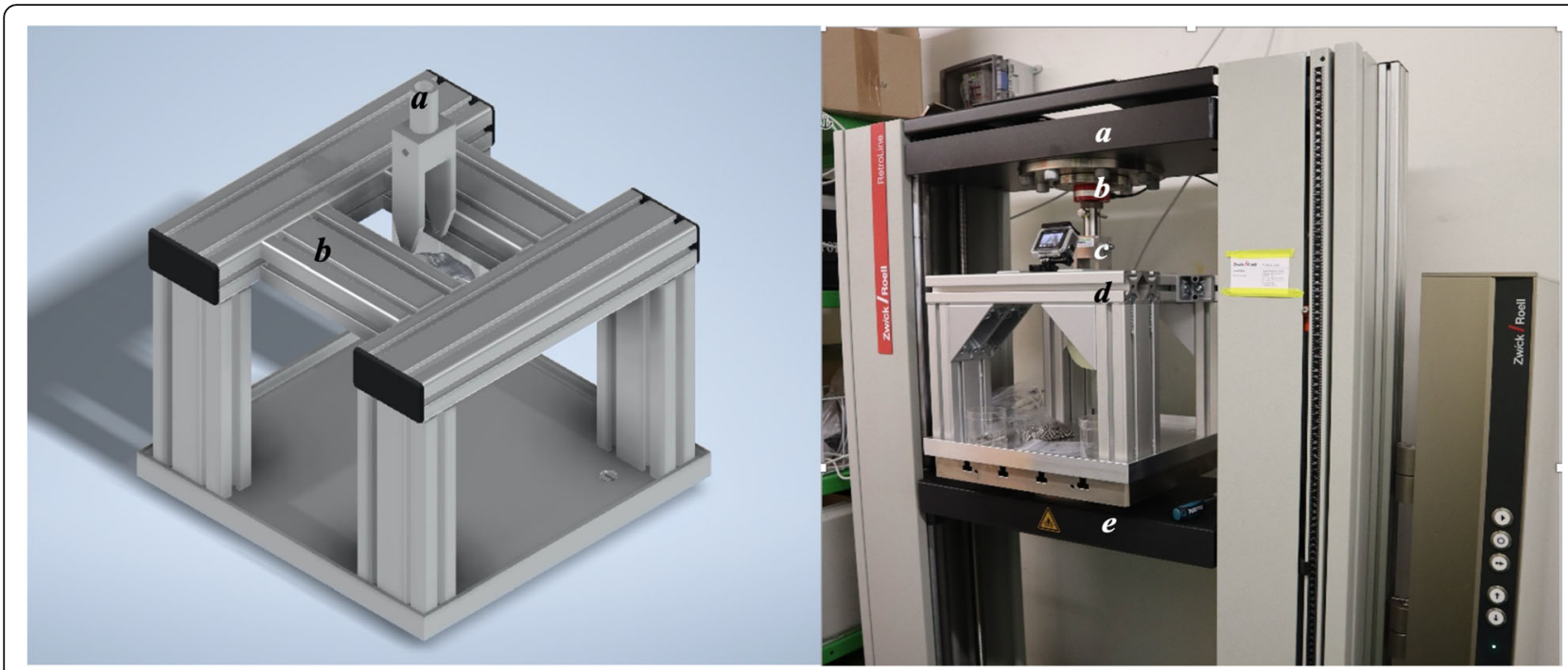

Fig. 2 Left: CAD model of the experimental setup (a: fastening claw; b: frame construction); right: test set-up (a: upper traverse; b: Force transducers; $\mathbf{c}$ : frame construction; $\mathbf{d}$ : under traverse)
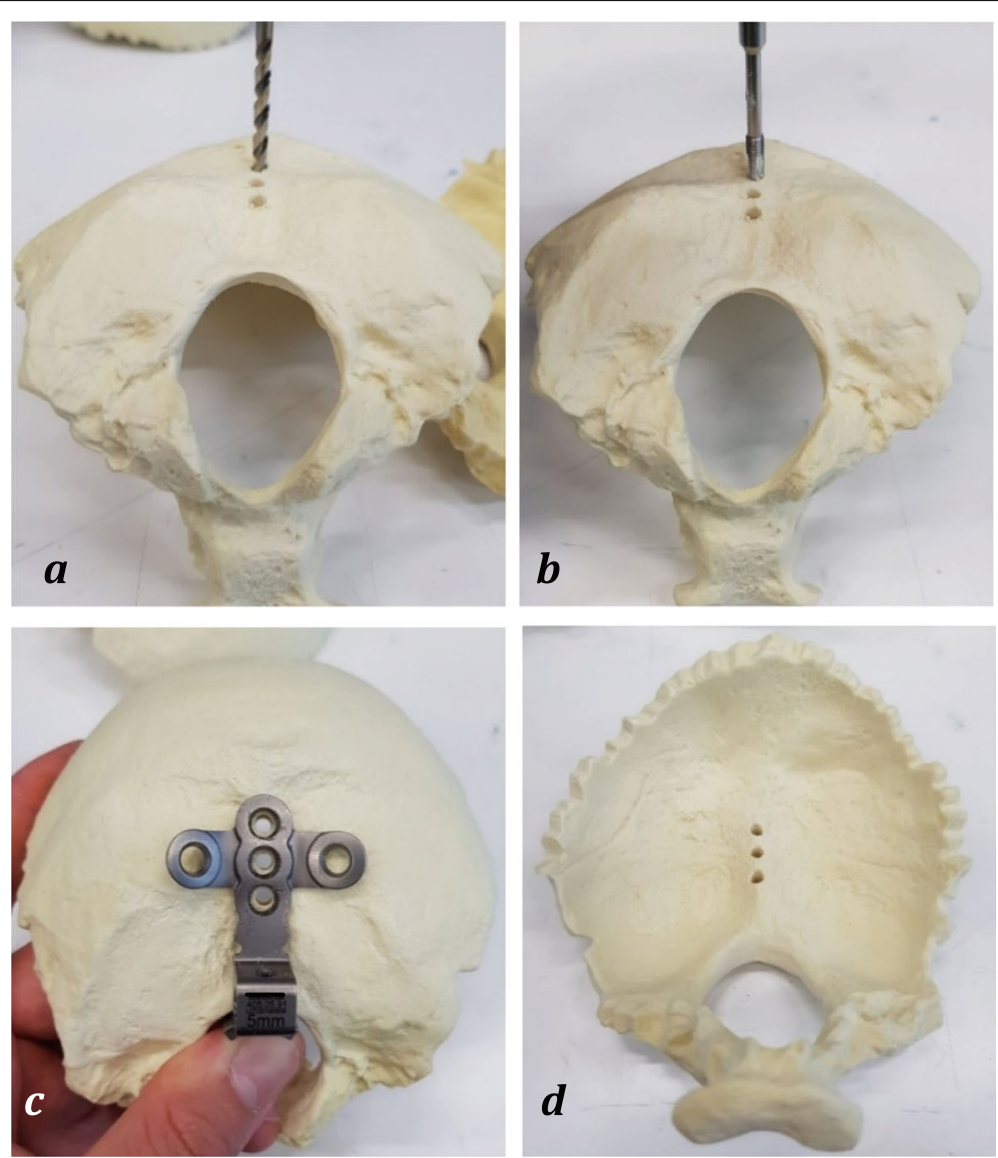

Fig. 3 With a drill, the diameter of which is $3.5 \mathrm{~mm}$, three through-holes are made in the occiput orthogonally to the top of the plate (a); each drill hole is then provided with a thread with the thread cutter $(\mathbf{b})$; the bores are concentric to the bores of the implant (c); artificial occiput with through-holes along the internal occipital crest (d) 
made in the artificial occiput orthogonally to the long axis of the plate (Fig. 3a). Each drill hole was then provided with a thread with the thread cutter (Fig. 3b). The implants of each test group were then positioned on the artificial occiput so that the three holes were centered concentrically one above the other (Fig. 3c, d). Then three occipital screws were screwed in with a hand screwdriver and tightened with a torque of $1 \mathrm{Nm}$ using a torque screwdriver (Wera - Wuppertal, Germany). Finally, the crossbar was pushed laterally into the plate and fixed with a torque of $1.6 \mathrm{Nm}$ using a torque limiter (W $+\mathrm{S}$ Solutions - Tuttlingen, Germany).

\section{Testing}

The implant construct consisting of the artificial occiput, plate, screws and crossbar was ensured into the experimental setup. The crossbar was pushed into the holes of the two force carriers of the fastening claw (Fig. 4). The artificial occiput was then placed in the center of the experimental setup and the crossbar was fixed to prevent it from slipping sideways. Afterwards, the test parameters were set using the testing machine software as follows: (1) test speed: $10 \mathrm{~mm} / \mathrm{min}$, with $25 \mathrm{~mm} / \mathrm{min}$ maximum (according to ASTM 2706 [13]); (2) preload: $5 \mathrm{~N}$; (3) force switch-off threshold: $90 \%$ force drop from F_max.

A GoPro camera (San Mateo, California, USA) was installed to document every measurement. 36 measurements were made (18 tests for each group). Failure force

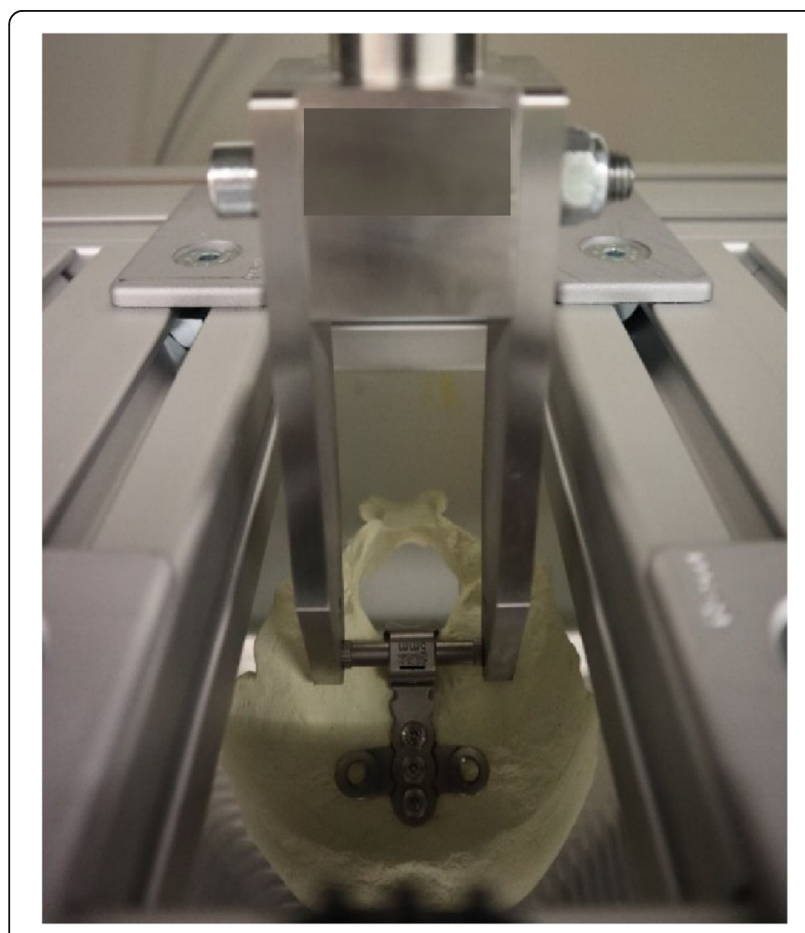

Fig. 4 The crossbar is pushed into the through holes of the two force carriers of the fastening claw and path were recorded with the MTM. Failure force is defined as the maximum reaction force under which failure occurs (F_max), while failure path is the travel path during which failure occurs $(\mathrm{dL})$. The information from the GoPro camera were just taken to document the process of pull out testing and to ensure the safety of the examiner. Furthermore, the information from the GoPro camera should be used to follow the pull out process in case of questionable results to have a chance to recapitulate the process afterwards. With this intention, no synchronization was needed between MTM and GoPro.

\section{Statistical analysis}

The statistical analysis was performed using the IBM SPSS software version 25. Mean, standard deviation and difference for F_max and dL were evaluated. The standard error (SE) was evaluated. The confidence interval (CI) was set at $95 \%$. The Shapiro-Wilk test was used to check if variables F_max and dL had normal distributions, with values of $P>0.1$ considered satisfactory. The unpaired $t$-test was used to determine whether there was a significant difference between the two test groups, with $P<0.05$ considered statistically significant.

\section{Results}

Group 1 (plate with hook) showed a mean failure force of $459.3 \pm 35.9 \mathrm{~N}$ and a mean failure path of $5.8 \pm 0.3$ $\mathrm{mm}$. Group 2 (plate without hook) showed a mean failure force of $323.9 \pm 20.2 \mathrm{~N}$ and a mean failure path of $7.2 \pm 0.4 \mathrm{~mm}$ (Table 1). The Shapiro-Wilk test score was not significant $(P>0.1)$, assuming that data were normally distributed. Group 1 had a statistically significant greater F_max $(+135.37 ; P>0.0001)$ and less $\mathrm{dL}(-1.52$; $P>0.0001)$ compared to group 2. Box plots of failure forces and paths are shown in Fig. 5, while Fig. 6 shows the different force-displacement curves. Data from this study demonstrate that the hook had a better performance concerning applied force.

\section{Discussion}

The occiput bone is flat and protects the contents of the posterior fossa, and furthermore, encircles on three sides the foramen magnum [4]. The occipitocervical junction is characterized by an extremely mobile transition segment of the upper spine and the interface between head and spine, respectively [9]. The function of the occipitocervical junction can impose significant stress under abnormal motion, trauma, or various spinal pathologies at that level [9]. Indications for occipitocervical junction fusion include traumatic injuries, tumors, degenerative instability, rheumatoid disease, and congenital anomalies of the occipitocervical junction. If surgical intervention 
Table 1 Overall results

\begin{tabular}{lllllll}
\hline Variable & Test group I $(\boldsymbol{n}=\mathbf{1 8})$ & Test group II $(\boldsymbol{n = 1 8 )}$ & Difference & SE & $\mathbf{9 5 \%} \mathbf{C l}$ & $\boldsymbol{P}$ \\
\hline F_max & $459.3 \pm 76.2$ & $323.88 \pm 42.9$ & 135.37 & 20.616 & 93.47 to 177.27 & $>0.0001$ \\
dL & $5.82 \pm 0.7$ & $7.24 \pm 0.8$ & -1.42 & 0.256 & -1.94 to -0.89 & $>0.0001$
\end{tabular}

is necessary, stabilization of the occipitocervical junction requires a robust fixation with an adequate implant. Many currently available fixation implants present an integrated plate-rod system, that often present difficulties for insertion of the $\mathrm{C} 1$ and $\mathrm{C} 2$ screws and require extensive bending to be adapted to the occipital bone [14]. Furthermore, these systems require a paramedian fixation of the screws, that thus cannot be placed in the thickest, median area of the occipital bone [14]. Newer, non-integrated implants present an attachment system between the occipital plate and the cervical rods and allow independent fixation of the cervical and occipital screws; however, screw placement around the midline limits the number of the screws that can be implanted [7]. For a safe and stable fixation we introduced a new, non-integrated implant with an additional hook for higher impact: the hook provides stability despite the use of a reduced number of occipital screws, while the non-integrated construct allows for implant feasibility. We found out that the additional hook in the occipital implant lead to a significantly higher failure force, and, at the same time, to a significantly lower failure path. As
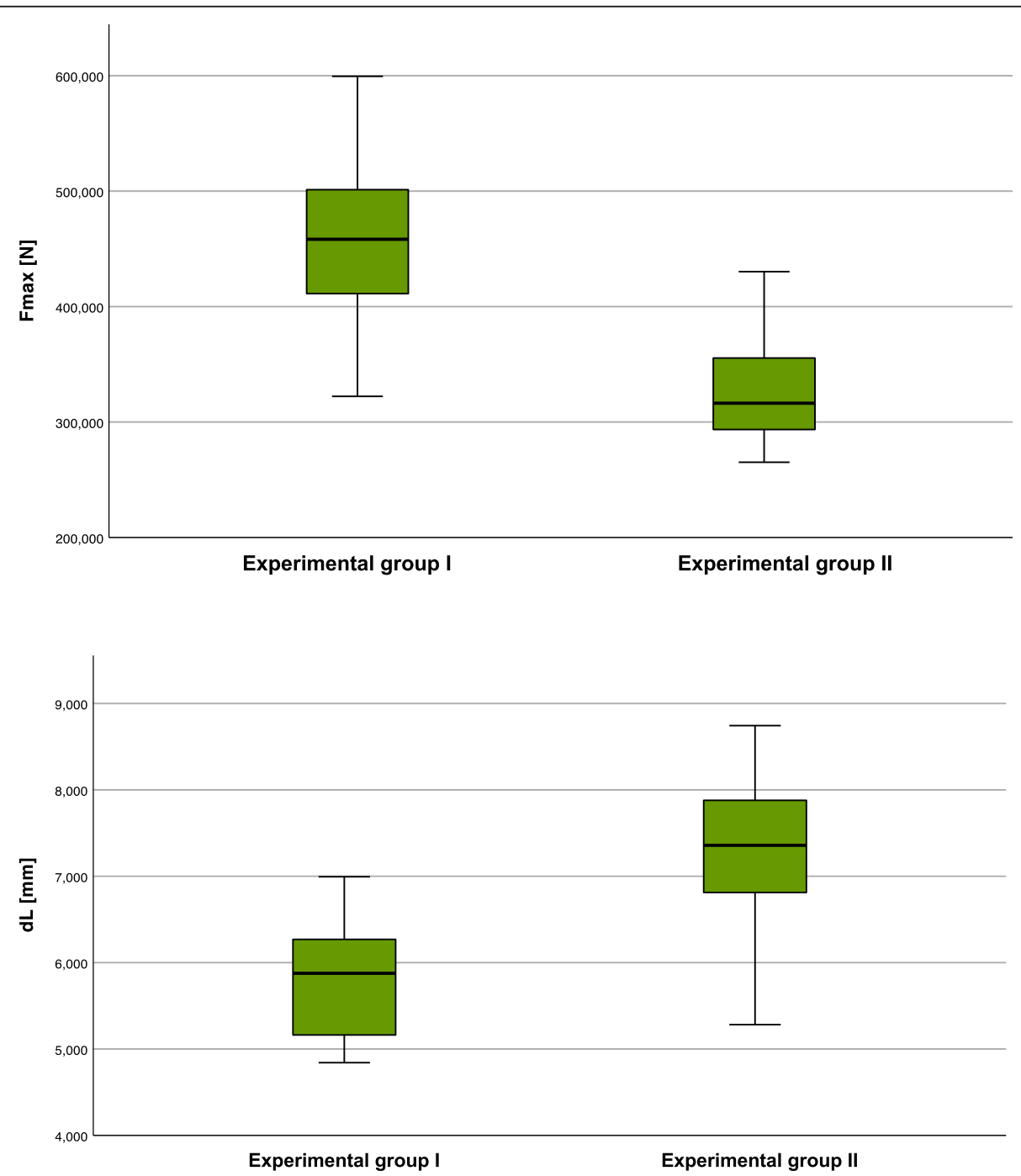

Fig. 5 Comparison of the failure forces and path of both test groups 

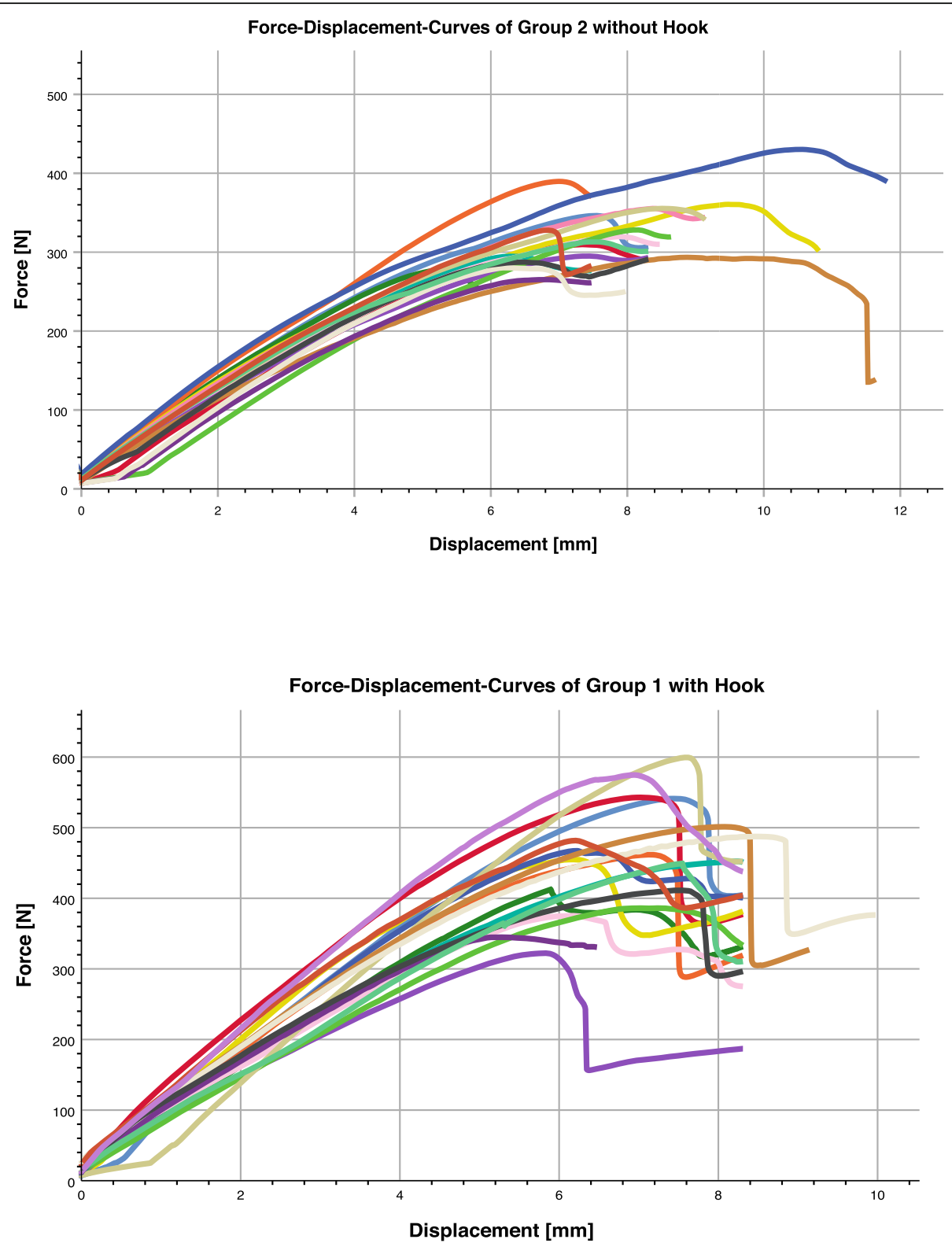

Fig. 6 Force - Displacement diagrams with and without hook (each test is reported in a different colour)

shown in Fig. 5, the mean failure force of test group 1, at $459.3 \mathrm{~N}$, is above the mean failure force of test group 2. Using the t-test, a significant difference between the mean values of both groups was demonstrated. The reason for the higher failure force is most likely the additional hook of the plate implant. The additional hook around the edge of the Squama occipitalis offers an additional form fit between the implant and the bony structure, that sums up with the frictional connection due to the screw, and ultimately leads to a higher pull-out or failure force. Furthermore, shown in Fig. 5, the measurement data from test group 1 had a greater spread than that of test group $2(323.9 \mathrm{~N})$. A possible explanation for this is provided by the different types of failure observed during the experiments. Most of the measurements resulted in the loss of the form fit due to the hook slipping out of the foramen magnum. In the remaining measurements, however, the hook broke out on one side at the edge of the squama occipitalis (Fig. 7). The different behavior of the implants during the test can possibly be explained by a poor anatomical adaptation of the hook to the edge of the squama occipitalis (Fig. 7).

In summary, it can be said that the additional hook of the implant brings an increase in the failure force due to the additional form fit between the implant and the bone. However, due to the shape of the hook, there is no 


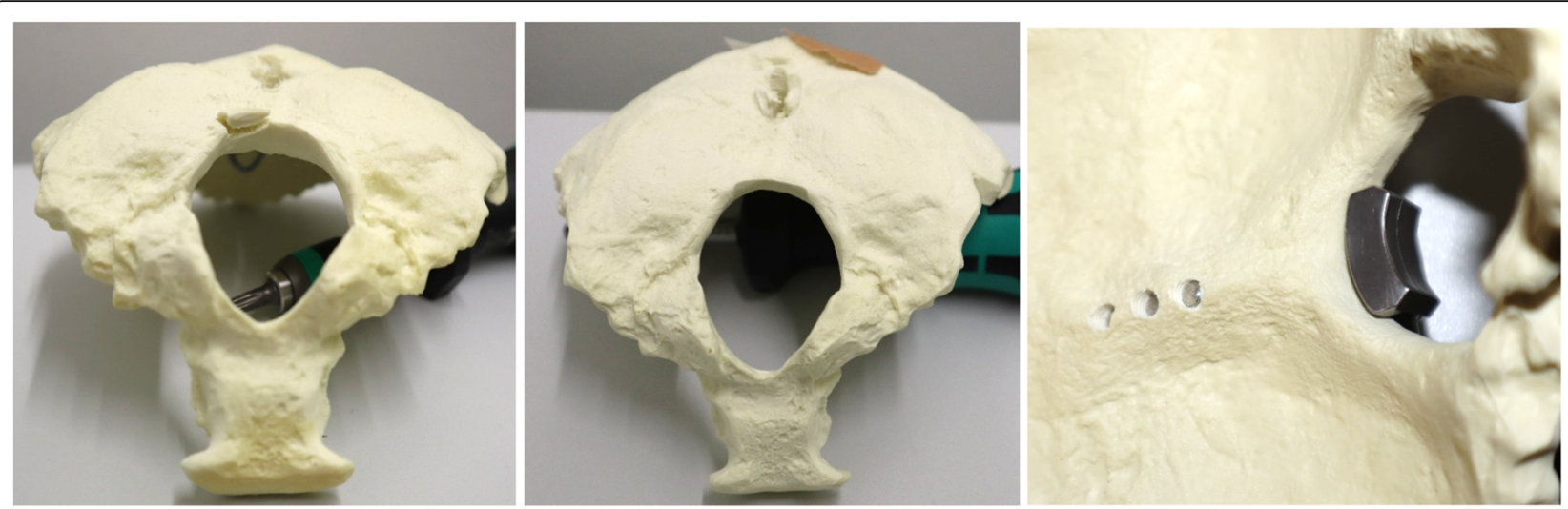

Fig. 7 From left to right: Broken edge of the occipital squama due to the hook breaking off; Deformed edge of the occipital squama due to the hook slipping; The shape of the hook is not adapted to the bone structure

reliable form fit, so that premature failure of the connection cannot be ruled out if the hook slips out. If the hook slips prematurely, the implant only shows the performance of an implant without a hook.

A comparison of the failure paths also shows that the mean failure path of test group 2 is $7.2 \mathrm{~mm}$, significantly higher than the mean failure path of test group 1 (5.8 $\mathrm{mm})$. A possible explanation for this finding is also provided by the operating principle of the connection between the implant and the artificial bone. Due to the lack of form fit in test group 2, the implant tends to shift even under low loads. As a result, by the time the connection fails, a greater distance has already been traveled.

As shown in Fig. 6, the spread of test group 2 is greater than that of test group 1. One possible explanation for this is the fact that the plate implant is connected to the occiput via three screw connections. Due to the lack of hooks on the implants of test group 2, the screws are subjected to tensile stress from the start of the test. Depending on the nature of the polyurethane foam, the tensile load causes the threads cut in the artificial bone to shear off and various screws to break out of the artificial bone. A failure therefore occurs under different failure paths (Fig. 8).

Beyond the biomechanical aspect, the use of a foramen magnum hook allows the use of an anatomical structure to additionaly anchor the construct, without requiring the creation of boreholes that may potentially lead to a damage to nervous or vascular structures. On the other end, cadaveric studies are required to investigate potential conflict of the hook with nervous structures in the foramen magnum, most of all in case of trauma or displacement.

Data presented here are from artificial bones (Sawbone ${ }^{\circ}$ ). The redeuced costs and time saved are some of the advantages of Sawbone ${ }^{\circ}$. Sawbones ${ }^{\circ}$ offer the possibility to improve hands-on skills for residents surgeons, to aquire/implement the physical abilities on new surgical tasks for surgeons $[15,16]$. Sawbones ${ }^{\oplus}$ demonstrated

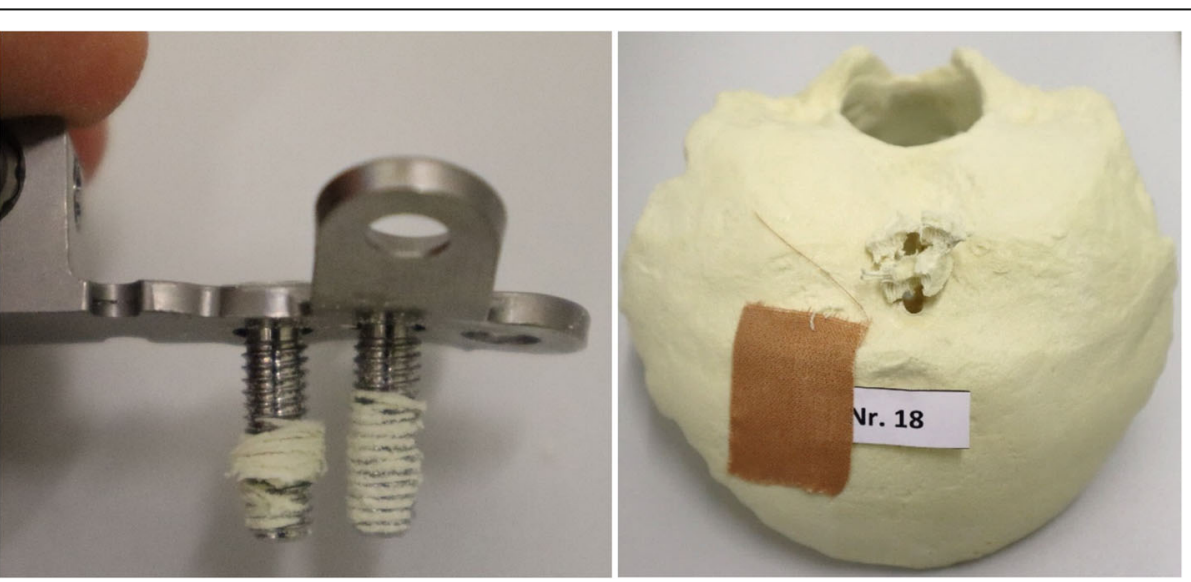

Fig. 8 Threads filled with artificial bone as a result of shearing (left); Fragments of the artificial bone as a result of the screws breaking out (right) 
to be a reliable alternative to the fresh cadaveric speciements for biomechanical testing purposes, and have been widely employed in several experimental settings [16-21]. On the other hand, Sawbones ${ }^{\bullet}$ offer a uniform and consisten density [22]; thereby, it suppresses interspecimen variability that occur in cadaveric experimental tests [23-25]. Thus, whist results may be more accurte, on the other hand they do not fully minic the heterogeneous caderic bone features. Furthermore, Sawbones ${ }^{\circ}$ lack vasculonervous and soft tissues structures, along with the lack of accurate proprioceptive feedback. Further associated limitations do apply, including that realistic loosening associated with physiologic loading is not present. Also bony remodeling does not take place at the implant interface. Another limitation of the hook implant is the lack of personalization. It is known that a mismatch between hook and bone thickness can limit the stability of the implant [8]. Due to the inadequate anatomical adaptation of the hook to the bone structure can slip off from the foramen magnum and lead to a loss of the observed biomechanical advantages. The redesign of the hook according to the anatomical conditions would lead to a more reliable form fit and thus to a more reliable fixation. Such a customized anatomical adaptation of the hook could potentially be a next step here - however, the time required to produce a customized implant may not be compatible with surgical timing in an emergency situation. Furthermore, an angle-stable connection between the occipital screw and the plate implant could be considered to optimize the implant. As the studies by Cronier et al. [26] show, the use of an angle-stable connection could further increase the failure force and thus achieve an overall more stable implant construct. Furthermore, complications arose from the inadvertent compression of implants on the cervical spinal canal [9]. It was discovered that these additional hook for the cervical spine may present complications not only because of proximity to the spinal cord but also because of the necessity of the hooks to firmly seat on the lamina [9]. Given these limitations, results form the present study must be interpret with caution. However, results from the present study should encourage future studies to investigate the behavior of this innovative implant for occipitocervical fusion in a cadaeric human setting, overcoming limitations of the Sawbone ${ }^{\bullet}$ models.

\section{Conclusion}

Medial plate with foramen magnum hook showed to be more stable that the plate without a hook. These new implants may represent a new tool in OCJ fixation, but further studies are required to investigate their behavior in an anatomical setting.
Acknowledgements

Dr. Migliorini and Dr. Baroncini equally contributed in this study.

\section{Authors' contributions}

FM: data interpretation, writing; $A B$ : data interpretation, writing; YEM: conception; VQ: conception; AP: conception; MM: statistical analysis; JG: supervision; MT: supervision; JE: experiments, revision. All the authors read and approved the final version of the manuscript.

\section{Funding}

This research was funded by Medicon eG - Chirurgische Instrumente, Gänsäcker 15, 78532 Tuttlingen, Germany. Open Access funding enabled and organized by Projekt DEAL.

\section{Availability of data and materials}

The datasets generated during and/ or analysed during the current study are available from the corresponding author on reasonable request.

\section{Declarations}

Ethics approval and consent to participate Not applicable.

\section{Consent for publication}

Not applicable.

\section{Competing interests}

The authors declare that they have any competing interests for this article.

\section{Author details}

'Department of Orthopaedic Surgery, RWTH Aachen University Hospital, Pauwelsstraße 30, 52074 Aachen, Germany. ${ }^{2}$ Department of Trauma Surgery, RWTH Aachen University Hospital, Aachen, Germany. Institute of Molecular and Cellular Anatomy, RWTH Aachen University, Aachen, Germany.

Received: 16 December 2020 Accepted: 22 February 2021

Published online: 06 March 2021

References

1. Benzel E. The cervical spine. 5th ed: Lippincott Williams \& Wilkins (LWW); 2012. p. 1666

2. Grob D. Posterior occipitocervical fusion in rheumatoid arthritis and other instabilities. J Orthop Sci. 2000:5(1):82-7.

3. Luksanapruksa P, Buchowski JM, Wright NM, Valone FH 3rd, Peters C, Bumpass DB. Outcomes and effectiveness of posterior occipitocervical fusion for suboccipital spinal metastases. J Neurosurg Spine. 2017;26(5):554-9.

4. Anderson PA, Oza AL, Puschak TJ, Sasso R. Biomechanics of occipitocervical fixation. Spine (Phila Pa 1976). 2006;31(7):755-61.

5. Frush TJ, Fisher TJ, Ensminger SC, Truumees E, Demetropoulos CK. Biomechanical evaluation of parasagittal occipital plating: screw load sharing analysis. Spine (Phila Pa 1976). 2009;34(9):877-84.

6. Hurlbert RJ, Crawford NR, Choi WG, Dickman CA. A biomechanical evaluation of occipitocervical instrumentation: screw compared with wire fixation. J Neurosurg. 1999;90(1 Suppl):84-90.

7. Ashafai NS, Visocchi M, Wasik N. Occipitocervical fusion: an updated review. Acta Neurochir Suppl. 2019;125:247-52.

8. Germaneau A, Vendeuvre T, Delmotte A, D'Houtaud S, Breque C, Petureau L, et al. Should we recommend occipital plate fixation using bicortical screws or inverted occipital hooks to optimize occipito-cervical junction fusion? A biomechanical study combining an experimental and analytical approach. Clin Biomech (Bristol, Avon). 2020;80:105173

9. Cheng BC, Hafez MA, Cunningham B, Serhan H, Welch WC. Biomechanical evaluation of occipitocervicothoracic fusion: impact of partial or sequential fixation. Spine J. 2008;8(5):821-6.

10. Akbay A, Isikay I, Orunoglu M. Occipitocervical fixation using occipital bone hooks and cervical lateral mass screws: analysis of 16 cases. Turk Neurosurg. 2014;24(4):558-64

11. Helgeson MD, Lehman RA Jr, Sasso RC, Dmitriev AE, Mack AW, Riew KD. Biomechanical analysis of occipitocervical stability afforded by three fixation techniques. Spine J. 2011;11(3):245-50. 
12. ASTM F1839-08. (2016) Standard Specification for Rigid Polyurethane Foam for Use as a Standard Material for Testing Orthopaedic Devices and Instruments. West Conshohocken, PA: ASTM International; 2016. Accessed at www.astm.org. Accessed on October, 2020

13. ASTM F2706-18 STMFO-CaO-C-TSICiaVM, ASTM International, West Conshohocken, PA, 2018. Available at www.astm.org. Accessed in October, 2020.

14. Joaquim AF, Osorio JA, Riew KD. Occipitocervical fixation: general considerations and surgical technique. Global Spine J. 2020;10(5):647-56.

15. Ryu R, Campbell A, Jain N, Stammen K, Yu E. Development of a spine surgical skills and written assessment for Orthopaedic surgery residents. J Surg Educ. 2019;76(4):1094-100.

16. Lewis CE, Peacock WJ, Tillou A, Hines OJ, Hiatt JR. A novel cadaver-based educational program in general surgery training. J Surg Educ. 2012;69(6): 693-8.

17. Ettinger S, Schwarze M, Yao D, Ettinger M, Claassen L, Stukenborg-Colsman C, et al. Stability of supramalleolar osteotomies using different implants in a sawbone model. Arch Orthop Trauma Surg. 2018;138(10):1359-63.

18. Schwarze M, Schonhoff M, Beckmann NA, Eckert JA, Bitsch RG, Jager S. Femoral Cementation in Knee Arthroplasty-A Comparison of Three Cementing Techniques in a Sawbone Model Using the ATTUNE Knee. J Knee Surg. 2019;34(3):258-66.

19. Caglar YS, Torun F, Pait TG, Hogue W, Bozkurt M, Ozgen S. Biomechanical comparison of inside-outside screws, cables, and regular screws, using a sawbone model. Neurosurg Rev. 2005;28(1):53-8.

20. Lee S, Kim JY, Hong J, Baek SH, Kim SY. CT-based navigation system using a patient-specific instrument for femoral component positioning: an experimental in vitro study with a Sawbone model. Yonsei Med J. 2018; 59(6):769-80.

21. Park CN, Nawabi DH, Christopher J, Conditt MA, Ranawat AS. Roboticassisted femoral osteochondroplasty is more precise than a freehand technique in a Sawbone model. J Hip Preserv Surg. 2015;2(2):136-44.

22. Yang SC, Liu PH, Tu YK. Pullout evaluation of sawbone experiment in different types of pedicle screws combined with bone cement augmentation for severe osteoporotic spine. Acta Bioeng Biomech. 2018; 20(2):55-64

23. Cristofolini L, Viceconti M. Mechanical validation of whole bone composite tibia models. J Biomech. 2000;33(3):279-88.

24. Heiner AD, Brown TD. Structural properties of a new design of composite replicate femurs and tibias. J Biomech. 2001;34(6):773-81.

25. Hao J, Nangunoori R, Wu YY, Rajaraman M, Cook D, Yu A, et al. Material characterization and selection for 3D-printed spine models. 3D Print Med. 2018;4(1):8.

26. Cronier P, Pietu G, Dujardin C, Bigorre N, Ducellier F, Gerard R. The concept of locking plates. Orthop Traumatol Surg Res. 2010. https://doi.org/10.1016/j. otsr.2010.03.008. Online ahead of print.

\section{Publisher's Note}

Springer Nature remains neutral with regard to jurisdictional claims in published maps and institutional affiliations.

Ready to submit your research? Choose BMC and benefit from:

- fast, convenient online submission

- thorough peer review by experienced researchers in your field

- rapid publication on acceptance

- support for research data, including large and complex data types

- gold Open Access which fosters wider collaboration and increased citations

- maximum visibility for your research: over $100 \mathrm{M}$ website views per year

At BMC, research is always in progress.

Learn more biomedcentral.com/submissions 